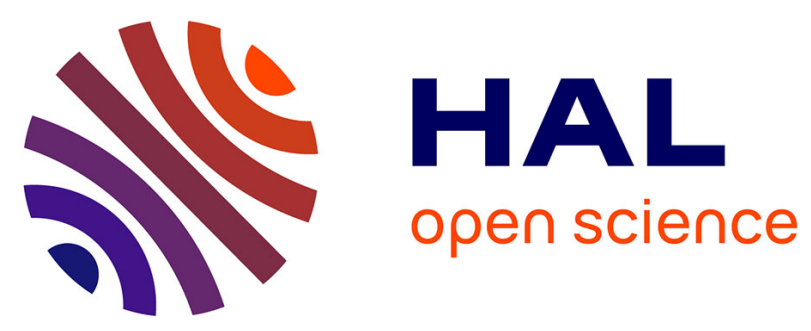

\title{
Divalent Thulium Crown Ether Complexes with Field-Induced Slow Magnetic Relaxation
}

Mathieu Xemard, Marie Cordier, Florian Molton, Carole Duboc, Boris Le Guennic, Olivier Maury, Olivier Cador, Grégory Nocton

\section{- To cite this version:}

Mathieu Xemard, Marie Cordier, Florian Molton, Carole Duboc, Boris Le Guennic, et al.. Divalent Thulium Crown Ether Complexes with Field-Induced Slow Magnetic Relaxation. Inorganic Chemistry, 2019, 58 (4), pp.2872-2880. 10.1021/acs.inorgchem.8b03551 . hal-02024309

\section{HAL Id: hal-02024309 \\ https://hal.science/hal-02024309}

Submitted on 13 May 2019

HAL is a multi-disciplinary open access archive for the deposit and dissemination of scientific research documents, whether they are published or not. The documents may come from teaching and research institutions in France or abroad, or from public or private research centers.
L'archive ouverte pluridisciplinaire HAL, est destinée au dépôt et à la diffusion de documents scientifiques de niveau recherche, publiés ou non, émanant des établissements d'enseignement et de recherche français ou étrangers, des laboratoires publics ou privés. 


\title{
Divalent Thulium Crown-ether Complexes with Field-Induced Slow Magnetic Relaxation
}

\author{
Mathieu Xémard, ${ }^{1}$ Marie Cordier, ${ }^{1}$ Florian Molton, ${ }^{2}$ Carole Duboc, ${ }^{2}$ Boris Le Guennic, ${ }^{3}$ Olivier Maury, ${ }^{4}$ \\ Olivier Cador ${ }^{3}$ and Grégory Nocton. ${ }^{1 *}$ \\ ${ }^{1}$ LCM, CNRS, Ecole polytechnique, Université Paris-Saclay, Route de Saclay, 91128 Palaiseau, France \\ ${ }^{2}$ Univ Grenoble Alpes, CNRS UMR 5250, DCM, F-38000 Grenoble, France. \\ ${ }^{3}$ Univ Rennes, CNRS, ISCR (Institut des Sciences Chimiques de Rennes) - UMR 6226, 35000 Rennes, France \\ ${ }^{4}$ Univ Lyon, ENS Lyon, CNRS, Université Claude Bernard Lyon 1, UMR 5182, Laboratoire de Chimie, 69342 Lyon \\ (France)
}

\begin{abstract}
The tailoring of the coordination chemistry around f-element centers is a crucial step for the development of compounds with slow magnetic relaxation, including single-molecule magnets (SMMs), which have great potential in molecular spintronics and for future quantum computing devices. Lanthanide ions are particularly interesting since the predominant electrostatic model of their bonding allows rationalizing their coordination symmetry. However, to the best of our knowledge, the redox properties of the lanthanides are not taken into account for the design of SMMs and therefore all SMMs reported to date contain lanthanide ions in their trivalent oxidation state. In this article, divalent lanthanide compounds presenting field induced slow magnetic relaxation are reported. The rational design and the synthesis of two $\mathrm{Tm}^{\mathrm{II}}$ complexes with the 18-Crown-6 ligand are presented along with their emission and EPR properties, which help to probe the desired nature of the ground state, i.e. maximizing the anisotropy. The observed magnetic properties demonstrate their slow magnetic relaxation behavior in a moderate external magnetic field.
\end{abstract}

\section{INTRODUCTION.}

Rare earth metal ions possess important intrinsic spectroscopic properties because of the filling of the $f$-shell orbitals, which are associated with a large orbital moment and relativistic effects. ${ }^{1-3}$ As a consequence, the spin orbit coupling constant is high, the coupling of the spin to the orbital angular momentum is very strong compared to the magnitude of the crystal field splitting, and a description of the properties in terms of the quantum number $\mathrm{J}$ is appropriate. ${ }^{4-6}$. This property has been particularly used in the development of optical devices, ${ }^{7-8}$ in which the emission wavelength is influenced not by the ligand set but mostly by the metal ion, which dictates the fingerprint energy of the spectrum. ${ }^{4}$ Another advantage of this unquenched orbital moment is found in the large magnetization reported for several lanthanide ions such as $\mathrm{Dy}^{\mathrm{III}}$, $\mathrm{Tb}^{\mathrm{III}}$ or $\mathrm{Er}^{\mathrm{III}} \cdot{ }^{9-10}$ This explains the great motivation for the use of lanthanide ions in the preparation of magnetic materials, in particular for Single-Molecule Magnets (SMMs): in less than a decade, the data concerning $4 f,{ }^{11-18}$ and also $5 f,,^{19-24}$ SMMs have dramatically increased.

In 2011, Rinehart and Long published a qualitative electrostatic model that highlights how the anisotropy of each element is influenced by the filling of $f$-orbitals. ${ }^{25}$ In this work, the authors rationalized which crystal field state $\left(\mathrm{m}_{j}\right.$ state) would be lowest - or highest in energy, depending upon the geometry around the lanthanide ion. An oblate metal-ion was predicted to need a strong axial coordination, while a prolate one would need a strong equatorial coordination to maximize the $\mathrm{m}_{J}$ microstate. ${ }^{25-26}$ This important step enabled a more rational approach for the design of potential lanthanide SMMs, ${ }^{11,13}$ and new records have been recently broken with organometallic dysprosium complexes behaving as a magnet up to $80 \mathrm{~K},{ }^{18,27-30}$ above the liquid nitrogen temperature, convincing the chemistry community that solid applications are feasible. ${ }^{31-32}$

However, if uranium compounds behave as SMMs in several oxidation states, + III and $+\mathrm{V},{ }^{33-34}$ lanthanide ions are only represented by their most common trivalent state ${ }^{11,13,21}$ and, to the best of our knowledge, no divalent lanthanide compound has been yet reported to exhibit a slow magnetic relaxation. This is unfortunate since the effective magnetic moments of divalent lanthanides can be extremely high, ${ }^{35-36}$ implying that such complexes are promising candidates. Additionally, if divalent and trivalent states can coexist in the same environment, a possible redox switch based on their slow magnetic relaxation properties could be anticipated. Such interesting properties have been described for systems with redox-active ligands and transition metal ions ${ }^{37-39}$ but not based on the oxidation states of the lanthanide ion yet because of the missing link.

If the coordination chemistry of the "classical" $\mathrm{Eu}^{\mathrm{II}}, \mathrm{Yb}^{\mathrm{II}}$ and $\mathrm{Sm}^{\mathrm{II}}$ complexes is currently most known, ${ }^{40-41}$ these compounds are not good candidates for the design of SMMs: $\mathrm{Eu}^{\mathrm{II}}$ with half-filled $f$ orbitals is isotropic, $\mathrm{Yb}^{\mathrm{II}}$ with closed-shell $f^{14}$ orbitals is diamagnetic and $\mathrm{Sm}^{\mathrm{II}}$ has a $J=0$ ground state. ${ }^{42-43}$ Thus, only the "non-classical" divalent lanthanides (all the others) can be promising candidates. One reason that can explain why none of these "non-classical" divalent lanthanide 
complexes have been reported yet as SMMs can be found in their intricate syntheses ${ }^{44}$ that usually necessitate bulky ligands to stabilize them: the symmetry and the coordination sphere around the metal center are barely rationalized since the primary aim is the stability. ${ }^{42,45-46}$ Consequently, we focused our attention on $\mathrm{Tm}^{\mathrm{II}}$ complexes that exhibit a $4 f^{13}$ electronic configuration and remain relatively accessible from a synthetic point of view. ${ }^{44,47-50}$ Only several groups, including ours, have tried to rationalize their synthetic approaches in combination with their spectroscopic properties. For example, Mills and coworkers described a bulky linear silylamide derivative of divalent thulium having a $\mathrm{m}_{J}=1 / 2$ ground state. ${ }^{51}$ In parallel, we have reported the luminescence and EPR properties on two simple precursors of divalent thulium, $\mathrm{TmI}_{2}(\mathrm{dme})_{3}$ and $\mathrm{Tm}(\mathrm{OTf})_{2}(\mathrm{dme})_{2} \cdot{ }^{48}$ Our conclusion was that the low-symmetry around the metal center imposes admixtures of the different $\mathrm{m}_{J}$ states, preventing any slow magnetic relaxation for these complexes. ${ }^{25}$ In addition, the presence of solvent molecules bonded to the $\mathrm{Tm}^{\mathrm{II}}$ center prevents the fine-control of their coordination sphere and complicates their spectroscopic analyses. In this context, we have focused on specific oxygen-based macrocycle ligand to impose the geometry and crystal field to the targeted complexes, specifically by using crown-ether ligands. ${ }^{52}$

The strategy used in this work is based on a rational ligand design approach to target divalent thulium complexes with large anisotropy by maximizing their ground crystal-field state. After the successful synthesis and characterization of such unprecedented compounds, we describe here two original divalent lanthanide complexes with slow magnetic relaxation. Such a report will open a new scope of studies devoted to manipulating the coordination and/or organometallic chemistry around divalent lanthanides, which offer additional coordination opportunities with respect to their trivalent congeners.

\section{RESULTS AND DISCUSSION.}

Synthesis and Solid-State Structure. The most successful strategy to stabilize a divalent thulium center consists in the use of bulky ligands including substituted trispyrazolylborate (Tp'), ${ }^{53-55}$ cyclopentadienyl (Cp') ligands ${ }^{44,56}$ and bulky silylamide ligands. ${ }^{50-51}$ However, these ligands are usually inducing strong axial ligand field, which is the opposite effect of what a prolate metal center requires to maximize the $\mathrm{m}_{J}$ configuration as confirmed by the $\mathrm{m}_{J}=1 / 2$ ground state found in the linear $\operatorname{Tm}\left\{\mathrm{N}\left(\mathrm{Si}^{i} \mathrm{Pr}_{3}\right)_{2}\right\}_{2}$ reported by Mills and co-workers. ${ }^{51}$ Based on calculations predicting a $\mathrm{m}_{J}=7 / 2$ ground state, the same authors reported a trigonal-planar $\operatorname{Tm}\left\{\mathrm{N}\left(\mathrm{Si}^{t} \mathrm{BuMe}\right)_{2}\right\}_{3}$ cationic complex. ${ }^{50}$ However, this complex is EPR silent and displays no out-of-phase ac signal, which was tentatively rationalized by quantum tunneling of the magnetization due to the hyperfine coupling with ${ }^{169} \mathrm{Tm} .{ }^{50}$

On the other hand, the synthesis of halide precursors of divalent thulium is known since the end of the 1990 's ${ }^{47}$ and their symmetry, in which two iodide anions are trans to each other, seems perfectly adapted to induce both small axial and stronger equatorial ligand field. However, their extreme sensitivity toward water and oxygen prevented spectroscopic analysis until recently. ${ }^{48}$

The main issue comes from the solvent molecules used to stabilize the $\mathrm{Tm}^{\mathrm{II}}$ coordination sphere in the equatorial plane: if a $\mathrm{TmI}_{2}(\text { thf })_{\mathrm{x}}$ can be prepared in thf solution at room temperature, ${ }^{44}$ the dark green powders obtained from crystalliza- tion at $-35^{\circ} \mathrm{C}$ are very sensitive to de-solvation processes. In dme, the story is different since stable crystals of $\mathrm{TmI}_{2}(\mathrm{dme})_{3}$ can be obtained ${ }^{47-48}$ and characterized by multiple solid-state spectroscopies. However, the presence of two different hapticities for the dme ligand breaks the equatorial symmetry and the spin-orbit ground state has a dominant admixture of $\mathrm{m}_{J}=5 / 2$ and $\mathrm{m}_{J}=3 / 2$. $^{48}$

In order to avoid these issues, we thought that pseudo-planar chelate ligands with oxygen donor such as crown-ether ligands would be good candidates. Their chemistry with trivalent lanthanides is relatively well-known with examples of crownether ligands of different sizes. ${ }^{52,57}$ The $12-\mathrm{c}-4$ is too small to chelate even the smallest lanthanides in their equatorial plane, ${ }^{58}$ whereas ytterbium fits well in 15-c-5 and 18-c-6 with examples of linear complexes showing a strong coordination in the equatorial plane. ${ }^{59-61}$ Additionally, recent examples of crown ether complexes were shown to exhibit SMM behavior. ${ }^{52}$ However, to the best of our knowledge, there is no example of crown-ether complexes of thulium.

The first synthetic attempts made with the 18-c-6 ligand consisted in mixing it into thf and dme solutions of $\operatorname{TmI}_{2}(\mathrm{~S})_{\mathrm{x}}$ ( $\mathrm{S}=$ thf or dme) at room temperature. This leads immediately to intractable dark powders, insoluble in any of the common organic solvents used in this particular chemistry. Therefore, a cold $\left(-35^{\circ} \mathrm{C}\right)$ toluene solution of $18-\mathrm{c}-6$ was diffused into a cold $\left(-35^{\circ} \mathrm{C}\right)$ thf solution of $\mathrm{TmI}_{2}(\text { thf })_{\mathrm{x}}$ (Scheme 1) leading to large dark crystals of $\mathrm{TmI}_{2}(18-\mathrm{c}-6)$ (1) in good yield (69 \%). These crystals were suitable for X-ray diffraction and Figure 2 shows an ORTEP of $\mathbf{1}$.

Scheme 1. Synthetic procedure for the formation of 1-3. $\mathrm{x}=$ 1.18 as determined by X-ray crystallography (See SI).

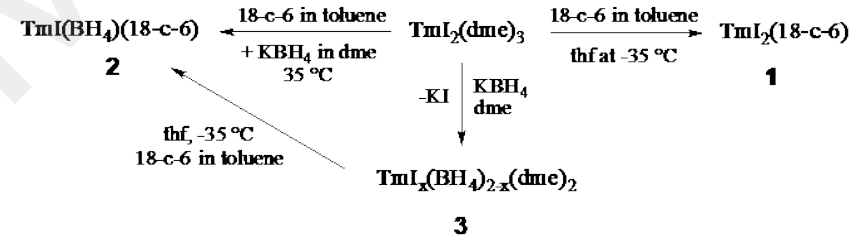

Crystals of $\mathbf{1}$ are insoluble in non-polar solvents (benzene, toluene, thf, dme, diethyether, methylcyclohexane). In pyridine, their color fades to pale brown when dissolving at low temperature, indicating that $\mathbf{1}$ is slowly oxidized into $\mathrm{Tm}^{\mathrm{III}}$ species. ${ }^{62-63}$ All attempts to crystallize this oxidized species failed. In solid-state, crystals of $\mathbf{1}$ are stable in the dark at $35^{\circ} \mathrm{C}$ but their color fades slowly when they are exposed either to room temperature or to light. Therefore, special care must be taken to conserve them and to investigate their spectroscopic properties. Thus, all data, including X-ray diffraction data, were reproduced multiple times on different batches. The light sensitivity of $\mathbf{1}$ was further studied at low temperature by emission spectroscopy (vide infra).

Because the iodide ligands could be at the origin of such reactivity, they were removed and replaced with borohydride ligands, $\mathrm{BH}_{4}^{-}$, as they were already used successfully with divalent thulium complexes. ${ }^{63-64}$ Borohydrides possess several advantages, such as a small ligand field and a usual tridentate coordination mode via the hydrogen atoms, fully compatible with an axial coordination mode. The $\mathrm{Tm}\left(\mathrm{BH}_{4}\right)_{2}(\mathrm{dme})_{2}$ complex was synthesized following the procedure of Nief. ${ }^{64} \mathrm{~A}$ toluene solution of $18-c-6$ was then used for the diffusion process as for the synthesis of $\mathbf{1}$; this synthesis only led to 
intractable materials due to the fast decomposition of the product. Therefore, in the aim of replacing only one iodide ligand, a single equivalent of potassium borohydride was added to a dme solution of $\mathrm{TmI}_{2}(\mathrm{dme})_{3}$. After few hours at rom temperature, the resulting brown solution was evaporated, extracted in thf, filtered off and was allowed to cool at $-35^{\circ} \mathrm{C}$ while a 18-c-6 cold toluene solution was layered on the top. This procedure yielded $\mathrm{X}$-ray suitable deep red - and highly sensitive crystals, of $\operatorname{TmI}\left(\mathrm{BH}_{4}\right)(18-\mathrm{c}-6)$ (2) in moderate yield (47 \%) in three days. The in situ addition of 1 equivalent of $\mathrm{KBH}_{4}$ in cold dme before layering a 18-c-6 cold toluene solution also yielded to the title complex but in a lower yield (Figure 1).

Crystallization attempts of the intermediate $\operatorname{TmI}_{\mathrm{x}}\left(\mathrm{BH}_{4}\right)_{1}$ ${ }_{\mathrm{x}}(\mathrm{dme})_{\mathrm{x}}(1 \leq \mathrm{x} \leq 2)$ compound in dme at low temperature result to the formation of dark brown-green crystals that were identified as $\mathrm{TmI}_{\mathrm{x}}\left(\mathrm{BH}_{4}\right)_{1-\mathrm{x}}(\mathrm{dme})_{2}$ (3) with $\mathrm{x}=1.18$ based on crystallographic data. Elemental analyses were not obtained for these compounds due to their high thermal and/or light sensitivity. Figure 1 and Figures S9-S11 show ORTEPs of 1-3, while main metric parameters and crystals information are gathered in the supporting information.
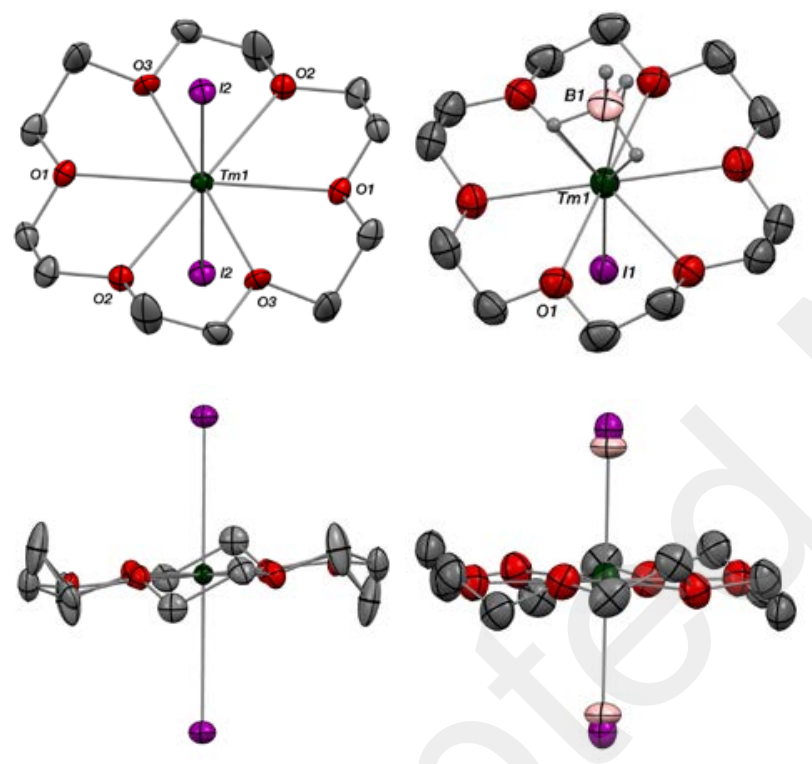

Figure 1. Solid-state structures of 1 (left) and $\mathbf{2}$ (right). Thermal ellipsoids plot are at $50 \%$ level. Disordered atoms in $\mathbf{1}$ and hydrogen atoms have been removed for clarity. Carbon atoms are in grey, oxygen atoms in red, thulium atoms in green, iodine atoms in purple and boron atom in pink.

Complex 1 crystallizes in the monoclinic I2/m space group, while 2 does in the trigonal R-3 space group. As a consequence of these space group symmetries, the iodine atom and the $\mathrm{BH}_{4}^{-}$anion in $\mathbf{2}$ are crystallographically disordered, while in $\mathbf{1}$, both iodine atoms are crystallographically identical featuring a I-Tm-I angle of $180^{\circ}$ imposed by the special position of the Tm atom. A position disorder is also present on the 18c-6 ligand in $\mathbf{1}$. In $\mathbf{1}$, the Tm-O distances range between 2.637(3) $\AA$ and 2.659(3) $\AA$ for an average distance of 2.65(1) $\AA$, while in 2, the Tm-O distance is 2.670(4) $\AA$. These distances are dictated by the crown-ether chelate, since in $\mathrm{TmI}_{2}(\mathrm{dme})_{3}$ the Tm-O distances are much shorter (between 2.46(1) $\AA$ and 2.55(1) A). ${ }^{47}$ Since there is no available data on thulium crown-ether complexes in the literature, the only possible comparison is with ytterbium derivatives featuring similar ionic radius: in $\mathrm{Yb}\left(\mathrm{NPh}_{2}\right)_{2}(18-\mathrm{c}-6),{ }^{60}$ the $\mathrm{Yb}^{\mathrm{II}}-\mathrm{O}$ bond lengths range between 2.507(3) $\AA$ and 2.658(3) $\AA$ (with a short average value of $2.594 \AA$ ), whereas in $\mathrm{Yb}(\mathrm{SCN})_{3}(18-\mathrm{c}-6),{ }^{61}$ the $\mathrm{Yb}^{\mathrm{III}}$-O lengths are much shorter $(2.476(5) \AA$ to $2.507(5) \AA)$.

The Tm-I distance is 3.1171(3) $\AA$ in $\mathbf{1}$ and 2.988(3) $\AA$ in 2. This difference between $\mathbf{1}$ and $\mathbf{2}$ is attributed to the crystallographic disorder with $\mathrm{BH}_{4}$ in $\mathbf{2}$. The Tm-I distances in $\mathbf{1}$ and $\mathbf{2}$ are shorter than those observed in $\mathrm{TmI}_{2}(\mathrm{dme})_{3}(3.13(2) \AA$ and 3.183(2) $\AA),{ }^{47-48}$ consistently with a weaker bonding in the equatorial plane. The Tm-B distance is 2.650(4) $\AA$, while the $\mathrm{Tm}-\mathrm{H}\left(\mathrm{BH}_{4}\right)$ distance is 2.4(1) $\AA$. These distances are agreeable with the Tm-B distances observed by Nief in $\mathrm{Tm}\left(\mathrm{BH}_{4}\right)_{2}(\mathrm{dme})_{2}$ that range between 2.632(4) $\AA$ and 2.656(5) $\AA$ and the Tm-H distances of the coordinated hydrogen atoms of the $\mathrm{BH}_{4}$ group found between 2.37(5) $\AA$ and 2.49(5) $\AA{ }^{64}$ Moreover, similar Tm-B (2.655 $\AA$ ) and Tm-H $\left(\mathrm{BH}_{4}\right)$ (between $2.459 \AA$ and $2.551 \AA$ ) distances are observed on the Tp'Tm $\left(\mathrm{BH}_{4}\right)$ complex. ${ }^{63}$ In the Tm ${ }^{\text {III }}$ complex $\mathrm{Cp}^{\text {ttt }}{ }_{2} \mathrm{Tm}\left(\mathrm{BH}_{4}\right)$, the $\mathrm{Tm}-\mathrm{H}\left(\mathrm{BH}_{4}\right)$ distances are much shorter $(2.14 \AA)$ but the Tm-B distance remains similar $(2.631 \AA) .{ }^{63}$ In this particular case, the steric influence of the bulky $\mathrm{Cp}^{\text {ttt }}$ ligands ${ }^{65,42}$ can explain this long Tm-B distance. Indeed, a homoleptic $\mathrm{Tm}\left(\mathrm{BH}_{4}\right)^{-}$complex was reported with shorter Tm-B distances (2.457 $\AA){ }^{66}$

Another consequence of the symmetry is the small deviation of the oxygen atoms from the equatorial plane: the maximal deviation is $0.249 \AA$ and $0.073 \AA$ in $\mathbf{1}$ and 2, respectively. The deviation angle between the I-Tm-I axis and the orthogonal direction to the equatorial plan is low: $1.5^{\circ}$ in $\mathbf{1}$ and $0^{\circ}$ in 2 . Therefore $\mathbf{1}$ and $\mathbf{2}$ represent promising examples of typically axial symmetry divalent thulium complexes, in which the equatorial ligand field is dominant, a prerequisite for maximizing the ground state $\mathrm{m}_{J}$ value. Spectroscopic properties (next paragraph) will provide more quantitative information on this matter.

Emission spectroscopy and EPR spectroscopy. Emissive properties of lanthanide ions have led to many applications for bio-imaging, sensing, fluoro-immunoassay or lighting devices in material science, but mostly with trivalent emissive lanthanide complexes. ${ }^{7}$ In the present work, the observation of an emission spectrum should allow the quantification of the crystal field splitting of the ground state and to establish crosscorrelation with magnetic and theoretical studies. ${ }^{6,67-68}$ However, the luminescence of divalent lanthanide complexes represents an under-explored area, with the exception of $\mathrm{Eu}^{\mathrm{II}}$ and to a lesser extend, $\mathrm{Yb}^{\text {II }}$ derivatives, whose emission arising from parity allowed intra-configurational $5 d-4 f$ transitions was extensively studied. ${ }^{68-69}$ We have recently reported the first emission spectra of molecular divalent thulium ions, viz. $\mathrm{Tm}(\mathrm{OTf})_{2}(\mathrm{dme})_{2}$ and $\mathrm{TmI}_{2}(\mathrm{dme})_{3}{ }^{48}$ that exhibit a characteristic $f$ - $f$ transition profile, thus evidencing an $f^{13}$ electronic structure, similar to that of $\mathrm{Yb}^{\mathrm{III}}$. This configuration gives two spinorbit states: the ground ${ }^{2} \mathrm{~F}_{7 / 2}$ and the excited ${ }^{2} \mathrm{~F}_{5 / 2}$ states, each of them being split by the ligand field, leading to multiple $\mathrm{m}_{J}$ states. In non-cubic symmetry, $m_{J}$ is comprised between $\pm 1 / 2$ and $\pm 7 / 2$ for the ground state $( \pm 1 / 2, \pm 3 / 2, \pm 5 / 2$, and $\pm 7 / 2$, i.e. 4 crystal-field states) and between $\pm 1 / 2$ and $\pm 5 / 2$ for the excited state $\left( \pm 1 / 2, \pm 3 / 2\right.$, and $\pm 5 / 2$, i.e. 3 crystal-field states). ${ }^{70-71}$ The emission spectrum of $\mathbf{1}$ was recorded at low temperature in solid-state. At $10 \mathrm{~K}$ and $77 \mathrm{~K}$, even if the signal is weak, a spectrum could be recorded (Figure 2). The low intensity of 
the emission spectrum can be explained by a rapid photobleaching under irradiation conditions. The photobleaching kinetics was studied and a linear decrease over time of the emission signal is observed (Figure S1), suggesting a possible light induced electron-transfer. The sample integrity can be easily checked after irradiation and indicates the decomposition of the dark purple crystals to a white powder. Our attempts to identify the final product have failed and further work is in progress in this direction. In contrast, the emission spectrum of $\mathbf{2}$ is more easily recorded since no photobleaching impacts the measurements.
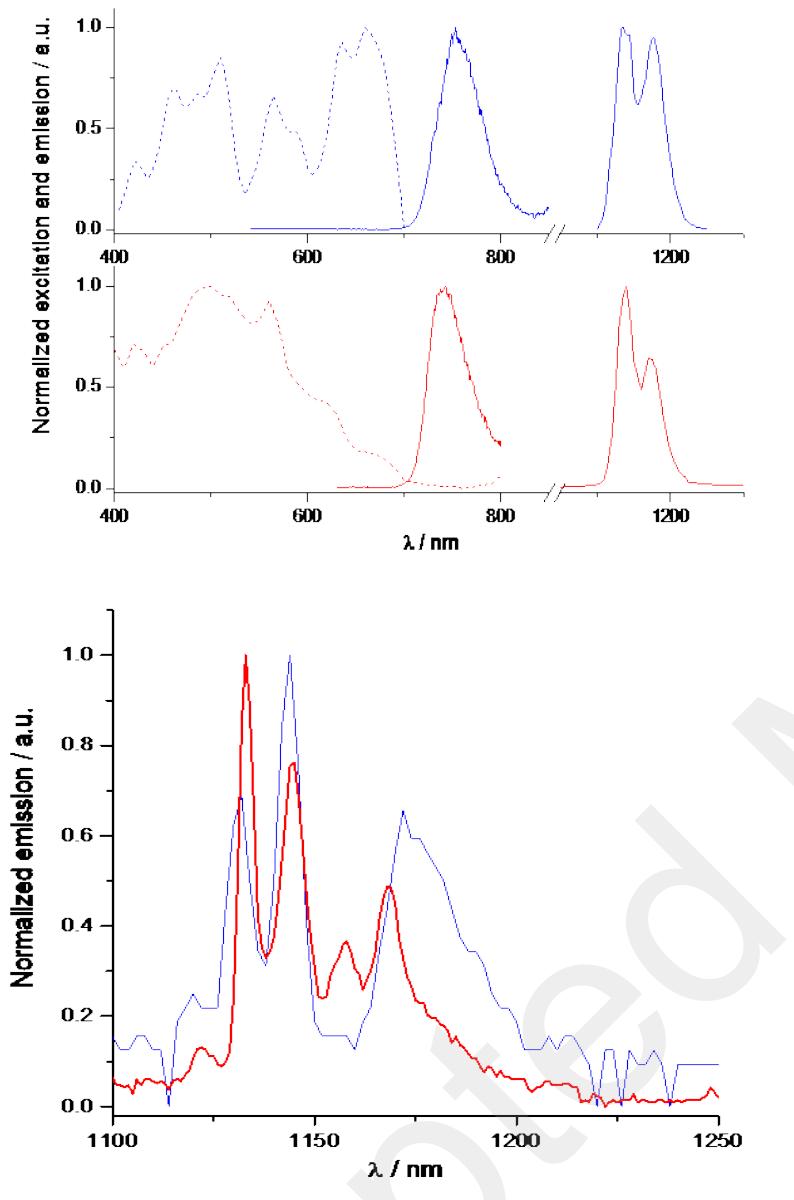

Figure 2. top) Solid state excitation (dashed lines; $1130 \mathrm{~nm}$ for 1, $1150 \mathrm{~nm}$ for $\mathbf{2}$ ) and emission (bold lines) spectra of $\mathbf{1}$ (blue) and $\mathbf{2}$ (red) at $77 \mathrm{~K}$. Bottom) Detail of the solid state emission spectrum recorded in the NIR with a higher resolution for $\mathbf{1}$ (blue) and 2 (red) at $77 \mathrm{~K}$ under a $520 \mathrm{~nm}$ excitation wavelength.

Upon excitation between 400-600 nm, 1 and 2 present two different emission responses located respectively in the red and NIR spectral range. The higher energy emission centered at $750 \mathrm{~nm}$ for $\mathbf{1}$ and $740 \mathrm{~nm}$ for $\mathbf{2}$ can be assigned to interconfigurational $5 d-4 f$ transitions. These transitions were previously reported in solid-state thulium compounds ${ }^{72-73}$ and recently by Mills and coworkers ${ }^{50}$ but not by us in $\mathrm{Tm}(\mathrm{OTf})_{2}(\mathrm{dme})_{2}$ and $\mathrm{TmI}_{2}(\mathrm{dme})_{3}{ }^{27}$ They are due to the relative proximity between the $5 d$ and $4 f$ orbitals in the divalent thulium complexes and their energies are more volatile because of the propensity of the $d$-orbitals energy to vary with the ligand field. Regarding the NIR emission, it is structured and is assigned to intra- configurational ${ }^{2} \mathrm{~F}_{5 / 2} \rightarrow{ }^{2} \mathrm{~F}_{7 / 2}$ transitions. The energy of the transition is in good agreement with a divalent thulium center and is shifted compared to $\mathrm{Yb}^{\mathrm{III}}$ because of the different spin-orbit coupling constant. Detail of the fine structure of these transitions is described in Figure 2. In the case of $\mathbf{1}$, three transitions are observed at $8834 \mathrm{~cm}^{-1}(1132 \mathrm{~nm}), 8741 \mathrm{~cm}^{-1}(1144 \mathrm{~nm})$ and $8518 \mathrm{~cm}^{-1}(1174 \mathrm{~nm})$ instead of the 4 expected in this symmetry but the transition at $1174 \mathrm{~nm}$ is clearly broader. For 2 a better resolution is obtained and five transitions with energies of $8909 \mathrm{~cm}^{-1}(1123 \mathrm{~nm}), 8824 \mathrm{~cm}^{-1}(1133 \mathrm{~nm}), 8739 \mathrm{~cm}^{-1}$ $(1144 \mathrm{~nm}), 8649 \mathrm{~cm}^{-1}(1156 \mathrm{~nm})$ and $8561 \mathrm{~cm}^{-1}(1168 \mathrm{~nm})$ are observed. On the spectrum recorded at $10 \mathrm{~K}$, the highest energy band is not present (Figure S2), evidencing the hot band character of this feature, i.e. a transition from an excited crystal field state of the emissive ${ }^{2} \mathrm{~F}_{5 / 2}$ spin-orbit state. ${ }^{6}$ Consequently, the spectrum of $\mathbf{2}$ displays the expected four transitions. The crystal field splitting of the ground state can thus be unambiguously established in the case of $\mathbf{2}$ giving the following $\mathrm{m}_{J}$ states $\left(0,85,190,263 \mathrm{~cm}^{-1}\right.$, Figure S3). Important conclusions can be drawn from the analysis of this spectrum: (i) the overall crystal field splitting is rather small $\left(263 \mathrm{~cm}^{-1}\right)$ and (ii) the ground $\mathrm{m}_{J}$ state is close to the first excited one (85 $\mathrm{cm}^{-1}$ ). Overall, the NIR emission spectra of $\mathbf{1}$ and $\mathbf{2}$ possess similar shapes, indicating a similar coordination environment. The effect of the replacement of an iodide ligand by a borohydride group leads only to a relatively modest decrease of the crystal field splitting $\left(316 \mathrm{~cm}^{-1}\right.$ vs $\left.263 \mathrm{~cm}^{-1}\right)$.

Emission spectra of the $4 f$ manifold are very efficient to quantify the overall crystal field splitting. However, it does not lead to the real nature of the low-lying $\mathrm{m}_{J}$ states. Fortunately, in $f^{13}$ configurations, it is possible to take advantage of low temperature EPR spectroscopy to probe the nature of the ground state. X-band EPR spectra recorded at $5 \mathrm{~K}$ for $\mathbf{1}$ and 2 are shown in Figure 3. Measurements were recorded on small crystals because of the very reactive nature of the complexes upon grinding. Therefore alignment of the crystals with the field can be observed during the experiments. This effect has been prevented by a manual shaking of the samples before each experiment, allowing a clear identification of the EPR features (Figure S4). However crystallites signs are still present in the spectra.

The spectrum of $\mathbf{1}$ indicates the presence of an axial symmetry with $\mathrm{g}_{/ /}$of 7.6 and $\mathrm{g}_{\perp}$ of 1.43 (Table S1, I and II on Figure 3, top). The anisotropy is large, $\Delta \mathrm{g}\left(\mathrm{g}_{/ /}-\mathrm{g} \perp\right)=6.17$, and is close to the predicted value for a pure $\mathrm{m}_{J}= \pm 7 / 2$ ground state $(\Delta \mathrm{g}=8))^{10}$ The spectrum of $\mathbf{2}$ was analyzed with a slight rhombic symmetry that could be induced by the heteroleptic coordination environment of Tm. However, this must be taken cautiously because of the crystallographic disorder of I and $\mathrm{BH}_{4}^{-}$. The spectrum was fitted with a $\mathrm{g}_{1}$ value of 7.00 (I, Figure 3 , bottom), while $\mathrm{g}_{2}$ and $\mathrm{g}_{3}$ are 1.78 and 1.39 (II and III, Figure 3, bottom), respectively. The anisotropy value, $\Delta \mathrm{g}\left(\mathrm{g}_{1}-\right.$ $\left.\mathrm{g}_{3}\right)$ is 5.61, i.e. within the same range than that of $\mathbf{1}$ in good agreement with a similar $\mathrm{m}_{J}= \pm 7 / 2$ contribution in the ground state and comparable coordination environments. The EPR spectra of both $\mathbf{1}$ and $\mathbf{2}$ are also markedly different and more isotropic than those recorded on other Tm ${ }^{\mathrm{II}}$ molecular compounds. $^{48,50-51}$

These spectroscopic data validate the predictions made on the role of equatorial coordination geometry in $f^{13}$ configurations: playing with the coordination geometry allows obtaining a maximized anisotropy in $\mathbf{1}$ and $\mathbf{2}$. In order to ascertain these 
predictions, we measured the magnetization behavior of these compounds.
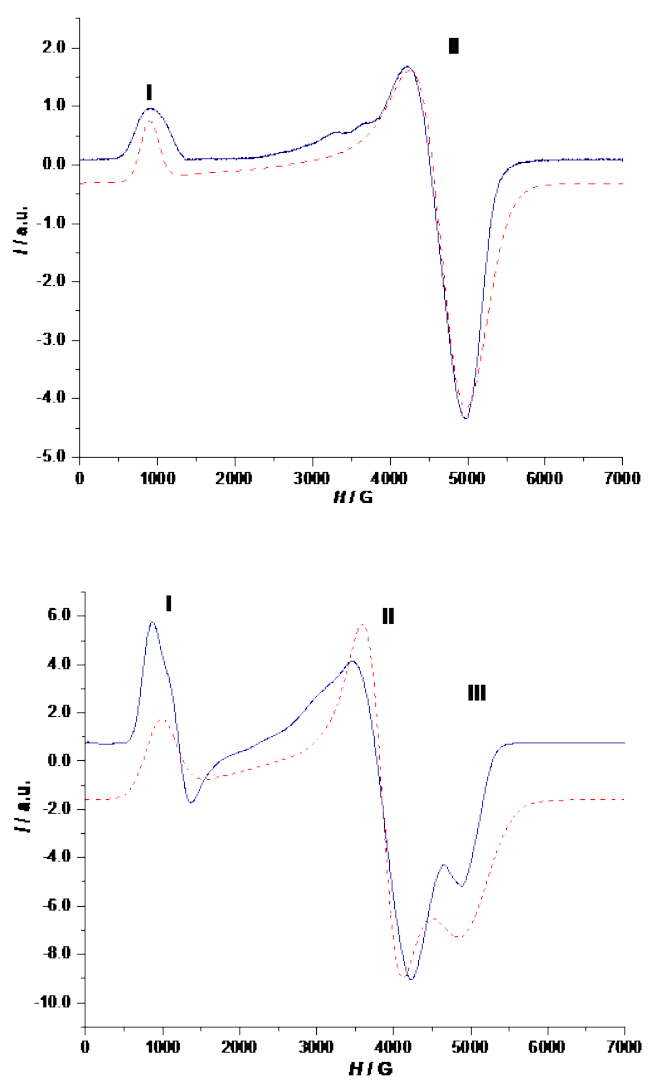

Figure 3. EPR spectra (X-Band) recorded in the solid state (powder) at $5 \mathrm{~K}$ for $\mathbf{1}$ (top) and for $\mathbf{2}$ (bottom) (experimental, blue and simulated spectrum, red).

Magnetic Characterization. Temperature dependent magnetic data were recorded in the solid-state (Figure 4). Room temperature $\chi_{\mathrm{M}} \mathrm{T}$ values are very similar for both $\mathbf{1}$ and $\mathbf{2}$ (2.35 vs. $2.34 \mathrm{~cm}^{3} . \mathrm{K} \mathrm{mol}^{-1}$, respectively) with lower values than that expected for a ${ }^{2} \mathrm{~F}_{7 / 2}$ ground state $\left(2.57 \mathrm{~cm}^{3} . \mathrm{K} \mathrm{mol}^{-1}\right)^{9}$ but in the range of the observed $\chi_{M} \mathrm{~T}$ values recorded for $\mathrm{Yb}^{\mathrm{III}}$ complexes. $\chi_{\mathrm{M}} \mathrm{T}$ decreases on cooling according to the thermal depopulation of crystal-field states. However, a notable difference between both compounds is observed below $50 \mathrm{~K}$ : at $2 \mathrm{~K}, 1.68$ $\mathrm{cm}^{3} . \mathrm{K} \cdot \mathrm{mol}^{-1}$ is reached for 1 and $1.17 \mathrm{~cm}^{3} \cdot \mathrm{K} \cdot \mathrm{mol}^{-1}$ for 2 . These values are lower than the ones estimated from EPR spectroscopy for $1\left(1.93 \mathrm{~cm}^{3} . \mathrm{K} \cdot \mathrm{mol}^{-1}\right)$ and $2\left(1.69 \mathrm{~cm}^{3} \cdot \mathrm{K} \cdot \mathrm{mol}^{-1}\right)$. At 2 $\mathrm{K}$, the magnetization saturates at very different values: 2.01 $\mathrm{N} \beta$ for 1 and $1.5 \mathrm{~N} \beta$ for 2 .

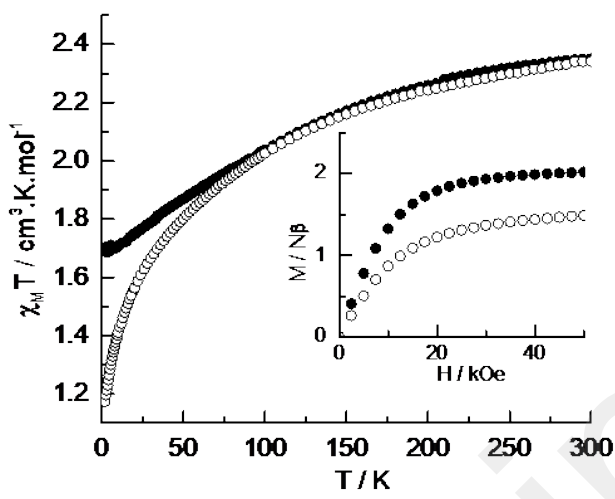

Figure 4. Static $\chi_{M} T$ and magnetization curves at $2 \mathrm{~K}$ (inset) measured on $\mathbf{1}$ (full dots) and on $\mathbf{2}$ (empty dots).

None of the two compounds show out-of-phase ( $\left.\chi_{M}{ }^{\prime \prime}\right)$ ac signal whatever the frequency $(v)$ and the temperature in the absence of an external dc field, but a strong clear signal emerges under moderate dc fields (Figures S5 and S6). The optimum field at which the relaxation is the slowest (the maximum on the $\chi_{M}$ "' vs. $v$ curves is at the lowest frequency) is estimated at 600 and 800 Oe for $\mathbf{1}$ and 2, respectively. At these fields, the relaxation times can be extracted at various temperature with an extended Debye model (Figure 5 and Tables S2S3). ${ }^{74}$ The thermal variations of the relaxation time for $\mathbf{1}$ and $\mathbf{2}$ are plotted on Figure S7. In the high temperature range, the thermal behavior can be modeled with an Arrhenius law (Figure S7) with activation energies of 35 and $16 \mathrm{~K}$ for $\mathbf{1}$ and 2, and $\tau_{0}=1.3 \times 10^{-7} \mathrm{~s}$ and $2.2 \times 10^{-6} \mathrm{~s}$, respectively. These barriers are in the range measured for $\mathrm{Yb}^{\mathrm{III}}$ complexes and are typical of $f^{13}$ compounds, in good agreement with $\mathrm{Tm}^{\mathrm{II}}$ centers. ${ }^{13}$ However, the two quantities do not match with the barriers heights estimated from luminescence and, furthermore, the Arrhenius law is verified only in the high temperature range. Thus, the thermal behaviors of the relaxation times were reinvestigated in the framework of a Raman+direct process ${ }^{75}(\tau$ $\left.{ }^{1}=\mathrm{C} \times \mathrm{T}^{\mathrm{n}}+\mathrm{AH}^{4} \mathrm{~T}\right)$. The two curves are perfectly reproduced with $\mathrm{C}=0.13(\mathrm{n}=6.73), \mathrm{A}=3.55 \times 10^{-10} \mathrm{Oe}^{-4} . \mathrm{s} . \mathrm{K}^{-1}$ for 1 and $\mathrm{C}=0.13$ $(\mathrm{n}=5.69), \mathrm{A}=4.44 \times 10^{-10} \mathrm{Oe}^{-4} \cdot \mathrm{s} \cdot \mathrm{K}^{-1}$ for 1 (Figure S7). This suggests that the relaxation does not occur through the first excited state but that under-the-barrier processes take place.

This point is crucial since it means that the slow relaxation is hampered via one or much probably multiple source(s). In their article on the trigonal-planar $\operatorname{Tm}\left\{\mathrm{N}\left(\mathrm{Si}^{t} \mathrm{BuMe}_{2}\right)_{2}\right\}_{3}$ complex, a molecule with a calculated $\mathrm{m}_{J}=7 / 2$ ground-state, Mills and co-authors tentatively justified the absence of slow relaxation by quantum tunneling arising from the hyperfine coupling with ${ }^{169} \mathrm{Tm}$ (I = 1/2, $100 \%$ abundance). ${ }^{50}$ The hypothesis could not be confirmed with EPR since the spectrum was silent. On the contrary, in the present work and in our previous report, ${ }^{45}$ the EPR broad lines were fitted using hyperfine couplingconstants below $2000 \mathrm{MHz}$, but the value of $\mathrm{A}_{\mathrm{Tm}}$ can be significantly larger in other complexes. ${ }^{51}$ Therefore, it is plausible that the strong variation of the hyperfine coupling constants is an important factor that would explain the under-the-barrier relaxation processes observed in $\mathrm{Tm}^{\mathrm{II}}$ complexes. However, due to the small number of complete data on divalent Tm complexes, a quantitative rationalization of the phenomenon seems premature at this stage. 


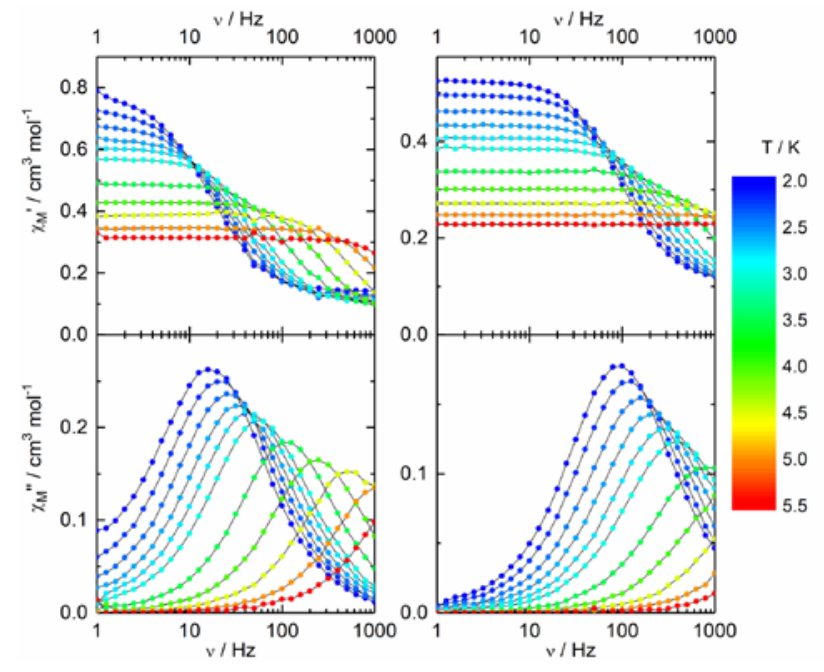

Figure 5: Frequency dependences of the in-phase (top) and outof-phase (bottom) components of the magnetic susceptibility of $\mathbf{1}$ (left) and 2 (right) measured under a 600 Oe field for $\mathbf{1}$ and 800 Oe field for 2; the temperature is varying from $2 \mathrm{~K}$ to $5.5 \mathrm{~K}$.

Computational studies. The nature and energy splitting of the crystal-field states in $\mathbf{1}$ and $\mathbf{2}$ as well as the magnetic properties were also investigated by wavefunction-based calculations (see Experimental section and Supporting Information for details). Unlike $\mathrm{Tm}(\mathrm{OTf})_{2}(\mathrm{dme})_{2}$ and $\mathrm{TmI}_{2}(\mathrm{dme})_{3}$, which ground and first excited spin-orbit states were exhibiting $\mathrm{m}_{J}$ admixures, ${ }^{48}$ the higher symmetry of $\mathbf{1}$ and $\mathbf{2}$ and the equatorial coordination of the strong oxygen donors allow the ground crystal-field state wavefunction to be closer to a pure configuration with a $\mid \pm 7 / 2>$ contribution of $90 \%$ in 1 at the SACASSCF level (Table S4). This is well illustrated by the calculated magnetization curve at $2 \mathrm{~K}$ and $\chi_{M} \mathrm{~T}$ in the lowtemperature region (Figure S8). Additionally, the nature of the ground state fits well with the EPR data and the $\mathrm{g}$ tensor is well reproduced albeit a slight deviation from the axial symmetry $\left(g_{x}=1.47 ; g_{y}=1.86 ; g_{z}=6.80\right)$. The excited states exhibit more spin admixtures of the different $m_{J}$ values and the overall small crystal field splitting is reproduced as well as the small energy gap between the ground state and the first excited state (93 $\mathrm{cm}^{-1}$ from emission spectra and $104 \mathrm{~cm}^{-1}$ from theory). As stated previously for $\mathrm{Tm}^{\mathrm{II}}$ complexes, ${ }^{48}$ and in some cases for $\mathrm{Yb}^{\mathrm{III}}$ systems, ${ }^{76-77}$ MS-CASPT2 treatment does not improve the description of the system with worst agreement with the experimental findings. SA-CASSCF approach was thus preferentially used in the case of $\mathbf{2}$. The first calculations carried out with the crystallographic atomic positions drastically underestimate the overall splitting $\left(166 \mathrm{~cm}^{-1}\right.$ vs. $263 \mathrm{~cm}^{-1}$ from luminescence). More importantly, the ground and first excited states are found almost pure with $0.90 \mid \pm 1 / 2>$ and $0.99 \mid \pm 3 / 2>$, respectively, far from the expected mainly $\mid \pm 7 / 2>$ ground state as evidenced by EPR and magnetometry. This strong discrepancy can find an explanation in a short Tm-I distance induced by the crystallographic disorder (vide supra). New calculations were thus carried out by progressively elongating the Tm-I distance (Table S5). While still qualitative, the computational description clearly evidences the modification of the wavefunction low-lying states. For a Tm-I distance of $3.4 \AA$, this model displays a ground state mainly composed of $\mid \pm 7 / 2>$ components and a g anisotropy in line with the experimental findings. While MS-CASPT2 treatment improves the overall energy splitting $\left(245 \mathrm{~cm}^{-1}\right)$, it is at the expense of the axiality of the ground state. These computational studies demonstrate that the influence of the geometric parameters on the electronic structure and therefore on the magnetic properties can be very subtle in lanthanide chemistry, reinforcing the need for high symmetry complexes to target the desired properties: the design of an appropriate ligand is the key.

\section{CONCLUSIONS.}

This work reports the slow magnetic relaxation behavior of divalent lanthanide complexes. The synthesis and x-ray crystal structure of two complexes of divalent thulium halide and borohydride with the popular 18-c-6 ligand are herein reported along with their emission and EPR spectra to probe the electronic nature of the ground state. These studies evidenced that the nature of the ground state is highly anisotropic for both complexes, due to their axial symmetry and the presence of strong donors in the equatorial plane. The magnetic moment of $\mathbf{1}$ and $\mathbf{2}$ relaxes slowly under a weak applied magnetic field at low temperature.

The subtle design of the coordination geometry around the divalent lanthanide ion allowed maximizing the crystal ground state values, i.e. the anisotropy, leading to the fieldinduced slow relaxation behavior. This strategy is rare for low-valent lanthanide complexes with high reduction properties because of their extreme reactivity that usually hampers the control of their coordination chemistry. This work shows how an adapted experimental protocol allows subtle coordination chemistry and can lead to the desired physical properties. This study will open new orientations in coordination and/or organometallic chemistry of lanthanide compounds since their divalent oxidation state - and the original geometries associated with them, ${ }^{78}$ can now be considered as valid for the design of compounds with slow magnetic relaxation.

\section{EXPERIMENTAL SECTION.}

General considerations. All reactions were performed using standard Schlenk-line techniques or in an argon filled glovebox (MBraun). All glassware was dried at $140^{\circ} \mathrm{C}$ for at least $12 \mathrm{~h}$ prior to use. thf, dme and toluene were dried over sodium, degassed and transferred under reduced pressure in a cold flask. $\mathrm{TmI}_{2}$ was purchased from Sigma Aldrich and used without further purification. 18-c-6 and $\mathrm{KBH}_{4}$ were sublimed before use.

Syntheses. 1. $\mathrm{TmI}_{2}(18-\mathrm{c}-6)$. A deep green solution of $\mathrm{TmI}_{2}(45.3$ $\mathrm{mg}, 107 \mu \mathrm{mol}$, 1 eq.) in THF was cooled to $-35^{\circ} \mathrm{C}$ before being layered with clean THF. A solution of 18-c-6 (28.3 mg, $107 \mu \mathrm{mol}, 1$ eq.) in toluene was then let to diffuse slowly at $-35^{\circ} \mathrm{C}$ in the $\mathrm{Tm}$ solution. The compound was obtained as big dark indigo needles (50.4 mg, $73.4 \mu \mathrm{mol}, 69 \%$ ).

2. $\operatorname{TmI}\left(\mathrm{BH}_{4}\right)(18-\mathrm{c}-6)$. A brown solution of $\mathrm{TmI}\left(\mathrm{BH}_{4}\right)(\mathrm{dme})_{3}(32.1$ $\mathrm{mg}, 55.2 \mathrm{mmol}, 1$ eq.) in THF was cooled to $-35^{\circ} \mathrm{C}$ before being layered with clean THF. A solution of 18-c-6 (14.6 mg, $55.2 \mu \mathrm{mol}, 1$ eq.) in toluene was then let to diffuse slowly at $-35^{\circ} \mathrm{C}$ in the $\mathrm{Tm}$ solution. The compound was obtained as highly sensitive small red blocks (15.1 mg, $26.1 \mu \mathrm{mol}, 47 \%)$.

$\mathrm{X}$-ray crystal structures. Single crystals were mounted on a Kapton loop using a Paratone N oil. An APEX II CCD BRUKER detector and a graphite Mo-K $\alpha$ monochromator were used for the data acquisition. All measurements were done at $150 \mathrm{~K}$ and a refinement 
method was used for solving the structure. Additional data for structure resolution is given in the supporting information.

Luminescence studies. Emission and absorption spectra of compounds 1 and $\mathbf{2}$ were measured on crushed crystals (powder) in sealed quartz tube. The luminescence spectra were measured using a Horiba-Jobin Yvon Fluorolog-3® spectrofluorimeter, equipped with a three slit double grating excitation and emission monochromator with dispersions of $2.1 \mathrm{~nm} / \mathrm{mm}$ (1200 grooves $/ \mathrm{mm}$ ). The steady-state luminescence was excited by unpolarized light from a $450 \mathrm{~W}$ xenon CW lamp and detected at an angle of $90^{\circ}$ by a red-sensitive Hamamatsu R928 photomultiplier tube. Spectra were reference corrected for both the excitation source light intensity variation (lamp and grating) and the emission spectral response (detector and grating). Near infrared spectra were recorded at an angle of $90^{\circ}$ using a liquid nitrogen cooled, solid indium/gallium/arsenic detector (850-1600 $\mathrm{nm})$. Two different samples for both $\mathrm{TmI}_{2}(18-\mathrm{c}-6)$ and $\mathrm{TmI}\left(\mathrm{BH}_{4}\right)(18-$ c-6) were measured leading to the same spectra once normalized.

EPR and magnetism. Powder EPR spectra were recorded with a Bruker EMX, equipped with an ER-4192 ST Bruker or ER-5106 QTW Bruker cavity for X- or Q-band, respectively. An Oxford Instruments ESR-900 continuous-flow helium cryostat was used for low temperature experiments. Samples were prepared under inert atmosphere in sealed quartz tubes. The X-band EPR spectra were measured on two independent samples, coming from different synthesis, leading to identical results. The obtained spectra were fitted using the Easyspin toolbox. ${ }^{79}$ The dc and ac magnetic susceptibility measurements were performed on solid polycrystalline samples with a Quantum Design MPMS-XL SQUID magnetometer. An applied magnetic field of $2 \mathrm{kOe}$ is used in the temperature range $2-20 \mathrm{~K}$, and $10 \mathrm{kOe}$ for temperatures above $20 \mathrm{~K}$, for the $\chi_{\mathrm{M}} \mathrm{T}$ vs. T curves. To avoid reorientation and sample degradation the microcrystals are trapped and slightly pressed between quartz wool in a sealed quartz tube. Furthermore, we voluntary degrade the sample after all the measurements have been performed to correct the data from $\mathrm{Tm}^{\text {III }}$ content and to verify that $\mathrm{Tm}^{\mathrm{III}}$ does not produce out-of-phase ac signal.

Computations. Wavefunction-based calculations were carried out on the Tm -based complexes $\mathbf{1}$ and $\mathbf{2}$ by using the SACASSCF/PT2/SI-SO approach (see SI for details).

\section{ASSOCIATED CONTENT}

\section{Supporting Information}

Additional information concerning luminescence properties, EPR, magnetism, theoretical studies and X-ray diffraction are given in the supporting information. The crystal structures have been deposited in the CCDC with numbers 1847987-1847989 for 1-3, respectively. The Supporting Information is available free of charge on the ACS Publications website.

\section{AUTHOR INFORMATION}

\section{Corresponding Author}

* greg.nocton@polytechnique.edu

\section{Funding Sources}

This project is part of an ANR (French National Research Agency) granted collaborative project (ANR-15-CE29-0019).

\section{ACKNOWLEDGMENT}

CNRS, Ecole polytechnique and the IR-RPE CNRS FR3443 network thanks for financial support. M.X. thanks the Direction Générale de l'Armement (DGA) for PhD funding. B.L.G. thanks the French GENCI/IDRIS-CINES center for high-performance computing resources.

\section{REFERENCES}

1. Dolg, M.; Stoll, H., Chapter 152 Electronic structure calculations for molecules containing lanthanide atoms. In Handbook on the Physics and Chemistry of Rare Earths, Elsevier: 1996; Vol. 22, pp 607-729.

2. Pyykko, P., Relativistic Effects in Structural Chemistry. Chem. Rev. 1988, 88, 563-594.

3. Pepper, M.; Bursten, B. E., The electronic structure of actinide-containing molecules: a challenge to applied quantum chemistry. Chem. Rev. 1991, 91, 719-741.

4. Ofelt, G. S., Intensities of Crystal Spectra of Rare-Earth Ions. J. Chem. Phys. 1962, 37,, 511-520.

5. Judd, B. R., Optical Absorption Intensities of Rare-Earth Ions. Phys. Rev. 1962, 127, 750-761.

6. van Vleck, J. H., The Puzzle of Rare-earth Spectra in Solids. J. Chem. Phys. 1937, 41, 67-80.

7. Bünzli, J.-C. G., Lanthanide Luminescence for Biomedical Analyses and Imaging. Chem. Rev. 2010, 110, 2729-2755.

8. Moore, E. G.; Samuel, A. P. S.; Raymond, K. N., From Antenna to Assay: Lessons Learned in Lanthanide Luminescence. Acc. Chem. Res. 2009, 42, 542-552.

9. $\quad$ Kahn O., Molecular Magnetism. John Wiley \& Sons: 1993.

10. Benelli, C.; Gatteschi, D., Introduction to Molecular Magnetism: From Transition Metals to Lanthanides. Willey-VCH: Weinheim, Germany, 2015.

11. Woodruff, D. N.; Winpenny, R. E. P.; Layfield, R. A., Lanthanide Single-Molecule Magnets. Chem. Rev. 2013, 113, 51105148.

12. Rinehart, J. D.; Fang, M.; Evans, W. J.; Long, J. R., Strong exchange and magnetic blocking in $\mathrm{N}_{2}{ }^{3-}$-radical-bridged lanthanide complexes. Nature Chem. 2011, 3, 538-542.

13. Pointillart, F.; Cador, O.; Le Guennic, B.; Ouahab, L., Uncommon lanthanide ions in purely 4f Single Molecule Magnets. Coord. Chem. Rev. 2017, 346, 150-175.

14. Rinehart, J. D.; Fang, M.; Evans, W. J.; Long, J. R., $\mathrm{A} \mathrm{N}_{2}{ }^{3-}$ Radical-Bridged Terbium Complex Exhibiting Magnetic Hysteresis at 14 K. J. Am. Chem. Soc. 2011, 133, 14236-14239.

15. Sorace, L.; Benelli, C.; Gatteschi, D., Lanthanides in molecular magnetism: old tools in a new field. Chem. Soc. Rev. 2011, 40, 3092-3104.

16. Allouche, F.; Lapadula, G.; Siddiqi, G.; Lukens, W. W.; Maury, O.; Le Guennic, B.; Pointillart, F.; Dreiser, J.; Mougel, V.; Cador, O.; Copéret, C., Magnetic Memory from Site Isolated Dy(III) on Silica Materials. ACS Cent. Sci. 2017, 3, 244-249.

17. Norel, L.; Darago, L. E.; Le Guennic, B.; Chakarawet, K.; Gonzalez, M. I.; Olshansky, J. H.; Rigaut, S.; Long, J. R., A Terminal Fluoride Ligand Generates Axial Magnetic Anisotropy in Dysprosium Complexes. Angew. Chem. Int. Ed. 2018, 57, 1933-1938.

18. Day, B. M.; Guo, F.-S.; Layfield, R. A., Cyclopentadienyl Ligands in Lanthanide Single-Molecule Magnets: One Ring To Rule Them All? Acc. Chem. Res. 2018, 51, 1880-1889.

19. Mills, D. P.; Moro, F.; McMaster, J.; van Slageren, J.; Lewis, W.; Blake, A. J.; Liddle, S. T., A delocalized arene-bridged diuranium single-molecule magnet. Nature Chem. 2011, 3, 454-460.

20. Mougel, V.; Chatelain, L.; Pecaut, J.; Caciuffo, R.; Colineau, E.; Griveau, J.-C.; Mazzanti, M., Uranium and manganese assembled in a wheel-shaped nanoscale single-molecule magnet with high spin-reversal barrier. Nature Chem. 2012, 4, 1011-1017.

21. Liddle, S. T.; van Slageren, J., Improving f-element single molecule magnets. Chem. Soc. Rev. 2015, 44, 6655-6669.

22. Rinehart, J. D.; Long, J. R., Slow Magnetic Relaxation in a Trigonal Prismatic Uranium(III) Complex. J. Am. Chem. Soc. 2009, 131, 12558-12559.

23. Rinehart, J. D.; Meihaus, K. R.; Long, J. R., Observation of a Secondary Slow Relaxation Process for the Field-Induced SingleMolecule Magnet $\mathrm{U}\left(\mathrm{H}_{2} \mathrm{BPz}_{2}\right)_{3}$. J. Am. Chem. Soc. 2010, 132, 75727573. 
24. Moro, F.; Mills, D. P.; Liddle, S. T.; van Slageren, J., The Inherent Single-Molecule Magnet Character of Trivalent Uranium. Angew. Chem. Int. Ed. 2013, 52, 3430-3433.

25. Rinehart, J. D.; Long, J. R., Exploiting single-ion anisotropy in the design of f-element single-molecule magnets. Chem. Sci. 2011, 2, 2078-2085.

26. Sievers, J., Asphericity of $4 \mathrm{f}$-shells in their Hund's rule ground states. Z. Phy. B Condens. Matter 1982, 45, 289-296.

27. Goodwin, C. A. P.; Ortu, F.; Reta, D.; Chilton, N. F.; Mills, D. P., Molecular magnetic hysteresis at 60 kelvin in dysprosocenium. Nature 2017, 548, 439.

28. Guo, F.-S.; Day, B. M.; Chen, Y.-C.; Tong, M.-L.; Mansikkamäki, A.; Layfield, R. A., A Dysprosium Metallocene Single-Molecule Magnet Functioning at the Axial Limit. Angew. Chem. Int. Ed. 2017, 56, 11445-11449.

29. Guo, F.-S.; Day, B. M.; Chen, Y.-C.; Tong, M.-L.; Mansikkamäki, A.; Layfield, R. A., Magnetic hysteresis up to 80 kelvin in a dysprosium metallocene single-molecule magnet. Science 2018, 362, 1400-1403.

30. McClain, K. R.; Gould, C. A.; Chakarawet, K.; Teat, S.; Groshens, T. J.; Long, J. R.; Harvey, B. G., High-temperature magnetic blocking and magneto-structural correlations in a series of dysprosium(III) metallocenium single-molecule magnets. Chem. Sci. 2018, 9, 8492-8503.

31. Bogani, L.; Wernsdorfer, W., Molecular spintronics using single-molecule magnets. Nature Mater. 2008, 7, 179.

32. Leuenberger, M. N.; Loss, D., Quantum computing in molecular magnets. Nature 2001, 410, 789.

33. Meihaus, K. R.; Long, J. R., Actinide-based singlemolecule magnets. Dalton Trans. 2015, 44, 2517-2528.

34. Liddle, S. T.; Slageren, J. v., Actinide Single-Molecule Magnets. In Lanthanides and Actinides in Molecular Magnetism, Wiley-VCH Verlag GmbH \& Co. KGaA: 2015; pp 315-340.

35. Meihaus, K. R.; Fieser, M. E.; Corbey, J. F.; Evans, W. J.; Long, J. R., Record High Single-Ion Magnetic Moments Through $4 \mathrm{f}^{\mathrm{n}} 5 \mathrm{~d}^{1}$ Electron Configurations in the Divalent Lanthanide Complexes $\left[\left(\mathrm{C}_{5} \mathrm{H}_{4} \mathrm{SiMe}_{3}\right)_{3} \mathrm{Ln}\right]^{-}$. J. Am. Chem. Soc. 2015, 137, 9855-9860.

36. Ryan, A. J.; Darago, L. E.; Balasubramani, S. G.; Chen, G. P.; Ziller, J. W.; Furche, F.; Long, J. R.; Evans, W. J., Synthesis, Structure, and Magnetism of Tris(amide) $\left[\mathrm{Ln}\left\{\mathrm{N}\left(\mathrm{SiMe}_{3}\right)_{2}\right\}_{3}\right]^{1-}$ Complexes of the Non-traditional +2 Lanthanide Ions. Chem. Eur. $J$. 2018, 24, 7702-7709.

37. Norel, L.; Feng, M.; Bernot, K.; Roisnel, T.; Guizouarn, T.; Costuas, K.; Rigaut, S., Redox Modulation of Magnetic Slow Relaxation in a 4f-Based Single-Molecule Magnet with a 4d CarbonRich Ligand. Inorg. Chem. 2014, 53, 2361-2363.

38. Fortier, S.; Le Roy, J. J.; Chen, C.-H.; Vieru, V.; Murugesu, M.; Chibotaru, L. F.; Mindiola, D. J.; Caulton, K. G., A Dinuclear Cobalt Complex Featuring Unprecedented Anodic and Cathodic Redox Switches for Single-Molecule Magnet Activity. $J$. Am. Chem. Soc. 2013, 135, 14670-14678.

39. Freedman, D. E.; Jenkins, D. M.; Iavarone, A. T.; Long, J. R., A Redox-Switchable Single-Molecule Magnet Incorporating $\left[\operatorname{Re}(\mathrm{CN})_{7}\right]^{3-}$. J. Am. Chem. Soc. 2008, 130, 2884-2885.

40. Evans, W. J., Tutorial on the Role of Cyclopentadienyl Ligands in the Discovery of Molecular Complexes of the Rare-Earth and Actinide Metals in New Oxidation States. Organometallics 2016, 35, 3088-3100.

41. Evans, W. J., The importance of questioning scientific assumptions: Some lessons from f element chemistry. Inorg. Chem. 2007, 46, 3435-3449.

42. Nocton, G.; Ricard, L., N-aromatic heterocycle adducts of bulky $\left[1,2,4-\left(\mathrm{Me}_{3} \mathrm{C}\right)_{3} \mathrm{C}_{5} \mathrm{H}_{2}\right]_{2} \mathrm{Sm}$ : synthesis, structure and solution analysis. Dalton Trans. 2014, 43, 4380-4387.

43. Van Vleck J. H., The Theory of Electric and Magnetic Susceptibilities. Oxford University Press: London, 1932.

44. Nief, F., Non-classical divalent lanthanide complexes. Dalton Trans. 2010, 39, 6589-6598.

45. Jacquot, L.; Xémard, M.; Clavaguéra, C.; Nocton, G., Multiple One-Electron Transfers in Bipyridine Complexes of Bis(phospholyl) Thulium. Organometallics 2014, 33, 4100-4106.
46. Cheisson, T.; Auffrant, A.; Nocton, G., eta(5)-eta(1) Switch in Divalent Phosphaytterbocene Complexes with Neutral Iminophosphoranyl Pincer Ligands: Solid-State Structures and Solution NMR (1)J(Yb-P) Coupling Constants. Organometallics 2015, 34, 5470-5478.

47. Bochkarev, M. N.; Fedushkin, I. L.; Fagin, A. A.; Petrovskaya, T. V.; Ziller, J. W.; BroomhallDillard, R. N. R.; Evans, W. J., Synthesis and structure of the first molecular thulium(II) complex: [TmI2(MeOCH(2)CH(2)OMe)(3)]. Angew. Chem. Int. Ed. Engl. 1997, 36, 133-135.

48. Xémard, M.; Jaoul, A.; Cordier, M.; Molton, F.; Cador, O.; Le Guennic, B.; Duboc, C.; Maury, O.; Clavaguéra, C.; Nocton, G., Divalent Thulium Triflate: A Structural and Spectroscopic Study. Angew. Chem. Int. Ed. 2017, 56, 4266-4271.

49. Szostak, M.; Procter, D. J., Beyond Samarium Diiodide: Vistas in Reductive Chemistry Mediated by Lanthanides(II). Angew. Chem. Int. Ed. 2012, 51, 9238-9256.

50. Goodwin, C. A. P.; Chilton, N. F.; Natrajan, L. S.; Boulon, M. E.; Ziller, J. W.; Evans, W. J.; Mills, D. P., Investigation into the Effects of a Trigonal-Planar Ligand Field on the Electronic Properties of Lanthanide(II) Tris(silylamide) Complexes $(\mathrm{Ln}=\mathrm{Sm}$, Eu, Tm, Yb). Inorg. Chem. 2017, 56, 5959-5970.

51. Goodwin, C. A. P.; Chilton, N. F.; Vettese, G. F.; Moreno Pineda, E.; Crowe, I. F.; Ziller, J. W.; Winpenny, R. E. P.; Evans, W. J.; Mills, D. P., Physicochemical Properties of Near-Linear Lanthanide(II) Bis(silylamide) Complexes ( $\mathrm{Ln}=\mathrm{Sm}, \mathrm{Eu}, \mathrm{Tm}, \mathrm{Yb})$. Inorg. Chem. 2016, 55, 10057-10067.

52. Maxwell, L.; Amoza, M.; Ruiz, E., Mononuclear Lanthanide Complexes with 18-Crown-6 Ether: Synthesis, Characterization, Magnetic Properties, and Theoretical Studies. Inorg. Chem 2018, 57, 13225-13234.

53. Kuhling, M.; McDonald, R.; Liebing, P.; Hilfert, L.; Ferguson, M. J.; Takats, J.; Edelmann, F. T., Stabilization of molecular lanthanide polysulfides by bulky scorpionate ligands. Dalton Trans. 2016, 45, 10118-10121.

54. Cheng, J.; Takats, J.; Ferguson, M. J.; McDonald, R., Heteroleptic Tm(II) complexes: One more success for Trofimenko's scorpionates. J. Am. Chem. Soc. 2008, 130, 1544-1545.

55. Momin, A.; Carter, L.; Yang, Y.; McDonald, R.; Essafi, S.; Nief, F.; Del Rosal, I.; Sella, A.; Maron, L.; Takats, J., To Bend or Not To Bend: Experimental and Computational Studies of Structural Preference in $\operatorname{Ln}\left(\operatorname{Tp}^{\mathrm{iPr}}{ }_{2}\right)_{2}(\operatorname{Ln}=\mathrm{Sm}$, Tm). Inorg. Chem. 2014, 53, 12066-12075.

56. Fieser, M. E.; MacDonald, M. R.; Krull, B. T.; Bates, J. E.; Ziller, J. W.; Furche, F.; Evans, W. J., Structural, Spectroscopic, and Theoretical Comparison of Traditional vs Recently Discovered $\mathrm{Ln}^{2+}$ Ions in the $[\mathrm{K}(2.2 .2$-cryptand $)]\left[\left(\mathrm{C}_{5} \mathrm{H}_{4} \mathrm{SiMe}_{3}\right)_{3} \mathrm{Ln}\right]$ Complexes: The Variable Nature of $\mathrm{Dy}^{2+}$ and $\mathrm{Nd}^{2+}$. J. Am. Chem. Soc. 2015, 137, 369382.

57. Arndt, S.; Spaniol, T. P.; Okuda, J., The first structurally characterized cationic lanthanide-alkyl complexes. Chem. Commun. 2002, 896-897.

58. Rogers, R. D.; Rollins, A. N.; Benning, M. M., fElement/crown ether complexes. 22. Preparation and structural characterization of lanthanide chloride complexes of 12-crown-4. Inorg. Chem. 1988, 27, 3826-3835.

59. Atwood, D. A.; Bott, S. G.; Atwood, J. L., Preparation and Structure of the $\left[\mathrm{YbCl}_{2} \cdot 15-\mathrm{CROWN}-5\right]^{+}$Cation, an Example of Seven-Coordinate Ytterbium. J. Coord. Chem. 1987, 16, 93-96.

60. Hitchcock, P. B.; Khvostov, A. V.; Lappert, M. F.; Protchenko, A. V., Ytterbium(II) amides and crown ethers: addition versus amide substitution. J. Organomet. Chem. 2002, 647, 198-204.

61. Bakker, J. M.; Deacon, G. B.; Junk, P. C., Rare earth thiocyanate complexes with 18-crown-6 co-ligands. Polyhedron 2013, 52, 560-564.

62. Fedushkin, I. L.; Nevodchikov, V. I.; Bochkarev, M. N.; Dechert, S.; Schumann, H., Russ. Chem. Bull. 2003, 52, 154-159.

63. Jaroschik, F.; Nief, F.; Le Goff, X. F.; Ricard, L., Synthesis and reactivity of organometallic complexes of divalent thulium with cyclopentadienyl and phospholyl ligands. Organometallics 2007, 26, 3552-3558. 
64. Momin, A.; Bonnet, F.; Visseaux, M.; Maron, L.; Takats, J.; Ferguson, M. J.; Le Goff, X.-F.; Nief, F., Synthesis and structure of divalent thulium borohydrides, and their application in epsiloncaprolactone polymerisation. Chem. Commun. 2011, 47, 1220312205.

65. Nocton, G.; Ricard, L., Reversible C-C coupling in phenanthroline complexes of divalent samarium and thulium. Chem. Commun. 2015, 51, 3578-3581.

66. Antsyshkina, A. S.; Sadikov, G. G.; Borisov, A. P.; Mashaev, V. D., Russ. J. Inorg. Chem. 2001, 46, 1273.

67. Pointillart, F.; le Guennic, B.; Cador, O.; Maury, O.; Ouahab, L., Lanthanide Ion and Tetrathiafulvalene-Based Ligand as a "Magic" Couple toward Luminescence, Single Molecule Magnets, and Magnetostructural Correlations. Acc. Chem. Res. 2015, 48, 28342842.

68. Pedersen, K. S.; Dreiser, J.; Weihe, H.; Sibille, R.; Johannesen, H. V.; Sorensen, M. A.; Nielsen, B. E.; Sigrist, M.; Mutka, H.; Rols, S.; Bendix, J.; Piligkos, S., Design of SingleMolecule Magnets: Insufficiency of the Anisotropy Barrier as the Sole Criterion. Inorg. Chem. 2015, 54, 7600-7606.

69. Suta, M.; Kühling, M.; Liebing, P.; Edelmann, F. T.; Wickleder, C., Photoluminescence properties of the "bent sandwichlike” compounds $\left[\mathrm{Eu}\left(\mathrm{Tp}^{\mathrm{iPr} 2}\right)_{2}\right]$ and $\left[\mathrm{Yb}\left(\mathrm{Tp}^{\mathrm{iPr} 2}\right)_{2}\right]$ - Intermediates between nitride-based phosphors and metallocenes. J. Lumin. 2017, 187, 62-68.

70. Kiss, Z. J., Energy Levels of Divalent Thulium in $\mathrm{CaF}_{2}$. Phys. Rev. 1962, 127, 718-724.

71. Eliseeva, S. V.; Bunzli, J.-C. G., Lanthanide Luminescence: Photophysical, Analytical, and Biological Aspects. Hänninen, P.; Härmä, H., Eds. Springer Series on Fluorescence: 2010; Vol. 7.
72. Grimm, J.; Wenger, O. S.; Krämer, K. W.; Güdel, H. U., $4 \mathrm{f}-4 \mathrm{f}$ and $4 \mathrm{f}-5 \mathrm{~d}$ excited states and luminescence properties of - doped $\mathrm{CaF}_{2}, \mathrm{CaCl}_{2}, \mathrm{SrCl}_{2}$ and $\mathrm{BaCl}_{2}$. J. Lumin. 2007, 126, 590-596.

73. Grimm, J.; Suyver, J. F.; Beurer, E.; Carver, G.; Güdel, H. U., Light-Emission and Excited-State Dynamics in $\mathrm{Tm}^{2+}$ Doped $\mathrm{CsCaCl}_{3}, \mathrm{CsCaBr}_{3}$, and $\mathrm{CsCaI}_{3}$. J. Phys. Chem. B 2006, 110, 20932101.

74. Cole, K. S.; Cole, R. H., Dispersion and Absorption in Dielectrics I. Alternating Current Characteristics. J. Chem. Phys. 1941, 9, 341-351.

75. Abragam A; Bleaney B, Electron Paramagnetic Resonance of Transition Ions. Clarendon Press: oxford, 1970.

76. Yi, X.; Bernot, K.; Le Corre, V.; Calvez, G.; Pointillart, F.; Cador, O.; Le Guennic, B.; Jung, J.; Maury, O.; Placide, V.; Guyot, Y.; Roisnel, T.; Daiguebonne, C.; Guillou, O., Unraveling the Crystal Structure of Lanthanide-Murexide Complexes: Use of an Ancient Complexometry Indicator as a Near-Infrared-Emitting Single-Ion Magnet. Chem. Eur. J. 2014, 20 1569-1576.

77. Belio Castro, A.; Jung, J.; Golhen, S.; Le Guennic, B.; Ouahab, L.; Cador, O.; Pointillart, F., Slow Magnetic Relaxation in Unprecedented Mono-Dimensional Coordination Polymer of Ytterbium Involving Tetrathiafulvalene-Dicarboxylate Linker. Magnetochemistry 2016, 2, 26.

78. Xémard, M.; Zimmer, S.; Cordier, M.; Goudy, V.; Ricard, L.; Clavaguéra, C.; Nocton, G., Lanthanidocenes: Synthesis, Structure and Bonding of Linear Sandwich Complexes of Lanthanides. J. Am. Chem. Soc. 2018, 140, 14433-14439.

79. Stoll, S.; Schweiger, A., EasySpin, a comprehensive software package for spectral simulation and analysis in EPR. $J$. Magn. Reson. 2006, 178, 42-55. 
Table of Contents
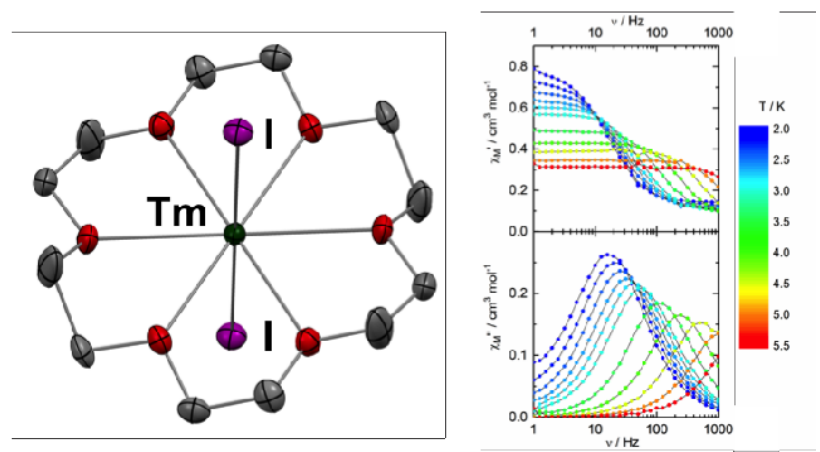